\title{
CRISPR/Cas9-Mediated Knock-in of Masu Salmon (Oncorhyncus Masou) Elongase Gene in the Melanocortin-4 (mc4r) Coding Region of Channel Catfish (Ictalurus Punctatus) Genome
}

\author{
Michael Coogan ( $\triangle$ mpc0038@auburn.edu ) \\ Auburn University \\ De Xing \\ Auburn University \\ Baofeng Su \\ Auburn University \\ Veronica Alston \\ Auburn University \\ Andrew Johnson \\ Auburn University \\ Mohd Khan \\ Bangladesh Agricultural University \\ Karim Khalil \\ Auburn University \\ Ahmed Elaswad \\ Auburn University \\ Shangjia Li \\ Auburn University \\ Jinhai Wang \\ Auburn University \\ Cuiyu Lu \\ Auburn University \\ Wenwen Wang \\ Auburn University \\ Darshika Hettiarachchi \\ Auburn University \\ Mei Shang \\ Auburn University \\ Tasnuba Hasin \\ Auburn University \\ Zhenkui Qin \\ Auburn University \\ Roger Cone \\ University of Michigan-Ann Arbor \\ lan Butts \\ Auburn University \\ Rex Dunham \\ Auburn University
}

Research Article 
Keywords: Channel catfish, Ictalurus punctatus, elongase, omega-3 fatty acid, melanocortin-4 receptor, mc4r, growth, gene editing, transgenesis, CRISPR/Cas9

Posted Date: February 9th, 2022

DOI: https://doi.org/10.21203/rs.3.rs-1251412/v1

License: 두 (i) This work is licensed under a Creative Commons Attribution 4.0 International License. Read Full License 


\section{Abstract}

Channel catfish, Ictalurus punctatus, have limited ability to synthesize $\Omega-3$ fatty acids due to a lack of elongases and desaturases. The cc $\beta A$-msElovl2 transgene containing masu salmon, Oncorhynchus masou, elongase gene driven by the common carp, Cyprinus carpio, beta-actin promoter was inserted into the channel catfish melanocortin-4 receptor ( $m c 4 r)$ gene site using the two-hit two-oligo with plasmid ( $2 \mathrm{H} 2 \mathrm{OP}$ ) method. The best performing sgRNA resulted in a knockout mutation rate of $92 \%$ with $69 \%$ homozygosity/bi-allelism, a knock-in rate of $54 \%$ and a simultaneous knockout/knock-in rate of $49 \%$. Fish simultaneously mutated with the cc $\beta A$-msElovl 2 transgene knock-in and $m c 4 r$ knockout (Elovl2) were $41.8 \%$ larger than controls at 6 months post-hatch. Mean eicosapentaenoic acid (EPA, C20:5n3) levels in Elov2 mutants and MC4R mutants were 121.6\% and $94.1 \%$ higher than in controls, respectively. Observed mean docosahexaenoic acid (DHA, C22:6n-3) and total EPA+DHA content was 32.8\% and $45.1 \%$ higher, respectively, in Elovl2 fish than controls. To our knowledge this is the first example of multiplexed genetic engineering and gene editing of a commercially important aquaculture species for valuable performance traits. With a high mutation rate, improved growth, and higher omega-3 fatty acid content, the use of Elovl2 channel catfish appears beneficial for application on commercial farms.

\section{Introduction}

Catfish production constituted approximately 68\% of total US domestic aquaculture production in 2015 (NOAA, 2016). However, catfish production has decreased by more than 50\% since its peak in 2003 (Hanson and Sites, 2015). The factors that caused the decline of catfish industry included intense competition from imported products from Asia, increased feed and fuel costs, and fish disease control problems (Wagner et al., 2002; FAO, 2020).

Growth and feed conversion efficiency are important traits affecting production costs and profitability. In catfish farming, feed is $60 \%$ of the variable cost (Robinson and Li, 2015). Feed conversion is also important to optimize for environmental reasons, both in resource use and greenhouse gas emissions (Hasan and Soto, 2017). Growth rate and feed conversion efficiency are highly correlated, especially in fast growing genotypes compared to slower growing genotypes (Dunham, 2011).

Surveys indicate that consumers in China, the US and globally are likely to be more receptive to genetically engineered (GE) food if it lowers food costs or if the GE food is of enhanced nutritional quality (Curtis et al., 2004; Zhang et al., 2010). Thus, one major objective of the current study is to enhance the nutritional quality of catfish through genetic engineering by improving omega-3 fatty acid (FA) levels.

The long-chain omega-3 polyunsaturated fatty acids (PUFAs), especially eicosapentaenoic acid (EPA, C20:5n-3), docosahexaenoic acid (DHA, C22:6n-3), and to a lesser extent, a-linolenic acid (ALA, C18:3n-3), have significant nutritional benefits in humans (Lauritzen et al. 2001). They are necessary for important biological processes of humans, such as lipid metabolism regulation, growth development stimulation, anticancer properties, anti-aging properties, immunoregulation, promoting cardiovascular health, aiding in weight loss, among others (Saunders et al., 2013). The American Dietetic Association and Dietitians of Canada recommend $500 \mathrm{mg} /$ day of EPA+DHA (Kris-Etherton et al., 2007). The long chain PUFAs EPA and DHA are predominantly derived from marine fish, while ALA is primarily synthesized in plants. However, global capture of wild fish is currently in decline due to overfishing and environmental problems, leading to long chain PUFAs being less available.

Farmed fish could serve as an alternative source for EPA/DHA. However, catfish lack an efficient endogenous pathway for converting the short/medium chain fatty acids into long-chain PUFAs, such as EPA and DHA, and subsequently have $\Omega-3$ FA levels 7-12 times less than $\Omega-3$ rich fish such as salmon (Wall et al., 2010).

Generation of fish lines capable of synthesizing EPA/DHA fatty acids from their feeds is a feasible solution. This might be achieved by overexpressing genes encoding enzymes involved in EPA/DHA biosynthesis. Fatty acid desaturases and elongases are among the key enzymes for the biosynthesis of PUFAs (Meesapyodsuk et al., 2007). Among them, $\Delta 6$-, $\Delta 5$ - and $\Delta 4$-desaturases and elongase are membrane-bound desaturases and fatty acid metabolic enzymes, which behave as important factors in EPA and DHA biosynthesis (Simopoulos, 2002). $\triangle 5$-desaturase uses eicosatetraenoic acid (ETA, 20:4n-3) as a substrate and allows the insertion of a double bond to produce EPA. The ETA fatty acid substrate is chain elongated (by elongases) from stearidonic acid (18:4n-3), a product of $\Delta 6$ desaturation of ALA. Further on, DHA is synthesized from EPA by the sequential chain elongation to docosapentaenoic acid (DPA, 22:5n3 ) and then to $24: 5 n-3$, followed by a $\triangle 6$-desaturation to $24: 6 n-3$, which is finally retroconverted by peroxisomes to DHA (Sprecher, 2000). Alternatively, $\triangle 4$-desaturase can convert DPA directly into DHA. 
Our laboratory has accomplished a high rate of targeted gene insertion. For example, $37 \%$ of fish integrated a masu salmon, Oncorhynchus masou, elongase transgene into exon 2 of luteinizing hormone (LH) gene of channel catfish (De et al., in preparation) using a modification of CRISPR/Cas9 termed 'Two-Hit by gRNA and Two-Oligos with a Targeting Plasmid' (2H2OP) (Yoshimi et al. 2016) with a great reduction in mosaicism. Huang et al. (2021) generated multiple families of $F_{1} \beta$-actin- $\Delta 5$ transgenic channel catfish. Desaturase $F_{1}$ channel catfish showed a 1.11-fold increase in $\Omega-3$ fatty acid levels measured as a change in ALA, DHA, and EPA compared to control counterparts. Levels of $\Omega-6$ fatty acids, linoleic acid (LA), dihomo-y-linolenic acid (DGLA) and the reproductively important arachidonic acid (ARA) decreased 1.11-fold in transgenic individuals. Individual $\Omega-3$ fatty acids ALA and DHA increased by $44.3 \%$ and $13.2 \%$, respectively. Precursors to $\Omega-6 \Delta$-desaturation, LA and DGLA, decreased $13.2 \%$ and $11.9 \%$, respectively.

The central melanocortin pathway regulates energy homeostasis in vertebrates as well as somatic growth and feed efficiency. Melanocortin receptors (MCRs) are transmembrane proteins and classified as G protein-coupled receptors. One of these MCRs is melanocortin-4 receptor (MC4R). The amino acid sequences of MC4R are highly conserved among different species (Stäubert et al., 2007). Polymorphisms in MC4R gene have been observed and linked to growth, carcass composition and meat quality traits. Natural mutations and knocking down mc4r in fish can affect growth (Song and Cone, 2007). In the swordtail fish, Xiphophorous nigrensis and $X$. multilineatus, small and large male morphs point to a single locus encoding $m c 4 r$ (Smith et al., 2015). Large male morphs in this species result from multiple copies of mutant forms of the receptor, at the $Y$ chromosome-encoded $\mathrm{P}$ locus, that appear to function in a dominant negative fashion, blocking activity of the wild-type receptor.

Copy number variants of the mc4rgene have a dramatic effect on the onset of puberty in Xiphophorus, but in the closely related species, medaka, Oryzias latipes, mc4r had no effect on reproduction or puberty, and the knock-out of mc4r retarded embryonic development (Liu et al., 2019). In contrast, in vitro studies on the anadromous fish, spotted scat, Scatophagus argus revealed that mc4r regulates gonadotropin releasing hormone ( $\mathrm{GnRH}$ ) as well as follicle stimulating hormone (FSH) and luteinizing hormone (LH) both directly and indirectly (by affecting the expression of $\mathrm{GnRH}$ ) (Jiang et al., 2017). These results indicate that mutations in the $m c 4 r$ gene may lead to infertility.

The major objective of this study was to simultaneously knock out the mc4rgene while inserting masu salmon elongase (Elovl2) transgene driven by the common carp $\beta$-actin promotor (ccßA-msElovl2) into channel catfish. Mutation rate and growth rate at different target sites were compared. Finally, fatty acid levels in mutants and controls were determined and compared.

\section{Results}

\section{Growth}

A total of $19 \mathrm{P}_{1}$ elongase transgenic mc4r knock-out channel catfish (Elovl2), 33 non-injected controls (NIC) and 31 injected-controls (InjCntrl) were generated in 2019. Elovl2 mutants were $56 \%$ and $14.59 \mathrm{~g}$ larger than NIC fish $(p=0.001)$ at 6 months post-hatch (Table 2). Elovl2 mutants were $29 \%$ and $9.27 \mathrm{~g}$ larger than Inj-Cntrl fish $(p=0.056)$. At 6 months post-hatch, Elovl2 mutants were $41.81 \%$ and 12.01 g larger than combined controls $(p=0.005)$. 
Table 1

Primers used to amplify partial sequences of channel catfish, Ictalurus punctatus, oligonucleotides to target specified regions for CRISPR/Cas9 cleavage and single-stranded oligo donor nucleotide (ssODN). Universal primer was used to bind oligonucleotides to Cas-9 protein. Bold letters indicate binding site to target sgRNAs. MC4R-A and MC4R-D were used to target various sequences in exon 1 of the channel catfish melanocortin-4 receptor $(m c 4 r)$ gene. MC4R-F and MC4R-R were used to amplify DNA segments flanking the target sites for sgRNAs in the catfish mc4r gene. PUC57 was used to target the ccßA-msElovl2 plasmid containing the masu salmon, Onchorhynchus masou, elongase gene driven by the common carp $\beta$-actin promoter. BsalElvol2_ ssODN1 and BsalElvol2_ssODN2 were used to flank the

cut site associated with the MC4R-A sgRNA to facilitate homologous recombination (HR) in the $m c 4 r$ gene. BsalElvol2_ ssODN3 and

BsalElvol2_ ssODN4 were used to flank the cut site associated with the MC4R-D sgRNA to facilitate HR in the $m c 4 r$ gene. Elovl2-F and Elovl2-R were used to amplify DNA segments flanking the target sites for sgRNAs in the cc $\beta A$-msElovl2 plasmid.

\begin{tabular}{|c|c|}
\hline Oligo sequence ( $5^{\prime}$ to $\left.3^{\prime}\right)$ & Oligo name \\
\hline AAAAGCACCGACTCGGTGCCACTTTTTCAAGTTGATAACGGACTAGCCTTATTTTAACTTGCTATTTCTAGCTCTAAAAC & $\begin{array}{l}\text { Universal } \\
\text { Primer }\end{array}$ \\
\hline GGAGATGGAGGACACGGAAG & MC4R-F \\
\hline GAGACATGAAGCAGACGCAATA & MC4R-R \\
\hline GTGATGGCGCTGATCACCAGCGG & MC4R-A \\
\hline CGGGATGCAGCATGCACACC & MC4R-D \\
\hline CTTGTCTGTAAGCGGATGCC & PUC57 \\
\hline TATCGAACGCGACAGAAACGGCTGTGATGGCGCTGATCACGCCGGGAGCAGACAAGCCCGTCAGGGCGCGTCAGCGGGTG & $\begin{array}{l}\text { BsalElvol2_ } \\
\text { ssODN1 }\end{array}$ \\
\hline GCAGCTCCCGGAGACGGTCACAGCTTGTCTGTAAGCGGATCAGCGGCAACCTGACCATCTCTGGAGACGTCGTGAAAAGC & $\begin{array}{l}\text { BsalElvol2_ } \\
\text { ssODN2 }\end{array}$ \\
\hline GAGGAGGTCTTGCGGATATGAACGTGTCGGAGCACCACGGGCCGGGAGCAGACAAGCCCGTCAGGGCGCGTCAGCGGGTG & $\begin{array}{l}\text { BsalElvol2_ } \\
\text { ssODN3 }\end{array}$ \\
\hline GCAGCTCCCGGAGACGGTCACAGCTTGTCTGTAAGCGGATGATGCAGCATGCACACCGGAACCACAGCCTGGGCGTGCAG & $\begin{array}{l}\text { BsalElvol2_ } \\
\text { ssODN4 }\end{array}$ \\
\hline CGAAATCCGTTCCTTTTTACTG & Elovl2-F \\
\hline CTGGCCTGTTCCTCATGTATTT & Elovl2-R \\
\hline
\end{tabular}

Table 2

Mean body weights (grams), sample size (N), standard deviation (SD) and coefficient of variation (CV) of Non-Inject Control, Inject-Control, pooled controls (CNTRL) and $\mathrm{P}_{1} \mathrm{cc} \beta \mathrm{A}-\mathrm{ms}$ Elovl2 transgenic/ $m c 4 r$ knock-out (Elovl2) channel catfish, Ictalurus punctatus, at 6 months post-hatch. The ccßA-msElovl2 transgene containing masu salmon, Oncorhynchus masou, elongase gene driven by the common carp, Cyprinus carpio, beta-actin promoter was inserted into the channel catfish melanocortin-4 receptor (mc4r) gene using the two-hit two-oligo with plasmid (2H2OP) method. Mutants and controls were kept in separate $50 \mathrm{~L}$ aquaria at a maximum density of $1 \mathrm{fish} / \mathrm{L}$ and fed daily to satiation. Overall, at 6 months post-hatch, ccßA-msElovl2 mutants were $41.81 \%$ and $12.01 \mathrm{~g}$ larger than pooled controls $(p=0.005)$. A paired t-test was used to compare treatments.

\begin{tabular}{|lllll|}
\hline \multicolumn{5}{|c|}{ Mean Body Weight (g) at 6 months post-hatch } \\
\hline Treatment & $\mathrm{N}$ & Mean & SD & CV \\
\hline Non-Inject Control & 33 & 26.15 & 10.74 & 41.05 \\
\hline Inject Control & 31 & 31.47 & 15.04 & 47.81 \\
\hline Elovl2 & 19 & 40.74 & 15.52 & 38.10 \\
\hline CNTRL & 64 & 28.73 & 13.17 & 45.85 \\
\hline Elovl2 & 19 & 40.74 & 15.52 & 38.10 \\
\hline
\end{tabular}

\section{Mutation Rate}

A total of 39 fish (MC4R-A) survived microinjection of CRISPR/Cas9, ccßA-msElovl2 transgene, and the MC4R-A sgRNA complex. A total of $36 / 39(92 \%)$ fish were mutated in the $m c 4 r$ target site and 21/39 (54\%) integrated the ccßA-msElovl2 plasmid at the $m c 4 r$ target site. 
A single band observed using the Elovl2 primer set indicates integration of the ccßA-msElovl2 transgene (Figure 2). Nearly half (49\%) of the 39 MC4R-A fish were mutated simultaneously in both the mc4rgene and with knock-in of the ccßA-msElovl2 transgene at the target site. A total of 53 fish survived microinjection of CRISPR/Cas9, ccßA-msElovl2 transgene, and the MC4R-D sgRNA complex. A total of $13 / 53$ (25\%) had a mutation in the mc4rtarget site and 3/53 (6\%) integrated the ccßA-msElovl2 plasmid (Table 3 ). None of the 53 MC4R$\mathrm{D}$ fish had both a mutation in the $m c 4 r$ gene and insertion of the ccßA-msElovl2 transgene. Multiple bands using the $m c 4 r$ primer set corresponded to expected cut sites in $m c 4 r$ gene (Figure 2). Each positive result was confirmed with a second gel. MC4R-A generated a greater rate of knockout of $m c 4 r(p<0.0001)$ and knock-in of ccßA-msElovl2 $(p<0.0001)$ than MC4R-D. Sequencing indicated insertion with complete fidelity into the channel catfish genome (See Supplemental Files Fig. S2).

Table 3

Mutation rates of two gRNA (MC4R-D and MC4R-A; see Table 1) targeting different loci in exon one of the channel catfish, Ictalurus punctatus, for CRISPR/Cas9 cleavage and simultaneous insertion of the cc $\beta A-m s E l o v l 2$ plasmid into the cut site. $P_{1}$ fish were generated in 2020. The ccßA-msElovl2 transgene containing masu salmon, Oncorhynchus masou, elongase gene driven by the common carp, Cyprinus carpio, betaactin promoter was inserted into the channel catfish melanocortin-4 receptor $(m c 4 r)$ gene using the two-hit two-oligo with plasmid (2H2OP) method. Approximately $50 \mathrm{~nL}$ of solution, composed of $1 \mu \mathrm{g} / \mu \mathrm{L}$ Cas 9 protein $(1 \mu \mathrm{L}), 400 \mathrm{ng} / \mu \mathrm{L}$ sgRNA 1 (MC4R-A or MC4R-D) (0.5 $\mu \mathrm{L}), 400 \mathrm{ng} / \mu \mathrm{L}$ sgRNA 2 (PUC57) $(0.5 \mu \mathrm{L}), 50 \mathrm{ng} / \mu \mathrm{L}$ donor plasmid $(1 \mu \mathrm{L})$, $100 \mathrm{ng} / \mu \mathrm{L}$ ssODN1 $(0.5 \mu \mathrm{L}), 100 \mathrm{ng} / \mu \mathrm{L}$ ssODN2 $(0.5 \mu \mathrm{L})$ and $60 \%$ phenol red $(1 \mu \mathrm{L})$, was injected into each embryo close to the blastodisc $15 \mathrm{~min}$ after fertilization using a glass capillary needle. Knockout and knock-in are denoted by $\mathrm{KO}$ and $\mathrm{KI}$, respectively. Logistic regression was used to determine significant difference in mutation rates between MC4R$D$ and MC4R-A.

\begin{tabular}{|lllll|}
\hline Treatment & MC4R KO & $\begin{array}{l}\text { ccßA-msElovl2 KI } \\
\text { Mutation Rate }\end{array}$ & $\begin{array}{l}\text { Moth } \\
\text { Mutation Rate }\end{array}$ & Homozygosity KO \\
\hline MC4R-D & $25 \%(13 / 53)$ & $6 \%(3 / 53)$ & $0 \%(0 / 53)$ & $38 \%(5 / 13)$ \\
\hline MC4R-A & $92 \%(36 / 39)$ & $54 \%(21 / 39)$ & $49 \%(19 / 39)$ & $69 \%(25 / 36)$ \\
\hline p-value & $1.14 \mathrm{e}-7$ & $1.12 \mathrm{E}-05$ & & 0.056 \\
\hline
\end{tabular}

\section{Fatty Acid Levels}

Mean EPA levels in Elov2 mutants and MC4R mutants were 121.6\% and $94.1 \%$ higher than in controls, respectively $(p=0.045 ; p=0.025)$ (Table 4). There were no statistically significant differences in DHA levels between any of the groups $(p=0.368)($ Table 4$)$. Mean observed DHA levels for Elovl2 mutants and MC4R mutants were $32.8 \%$ and $21.4 \%$ higher than controls, respectively (Figure 3a). Overall observed, levels of EPA+DHA were 45.1\% and 4.3\% higher in Elovl2 fish than controls and MC4R fish, respectively. There was no significant difference in alpha-Linolenic acid (ALA, C18:3n-3) or arachidonic acid (ARA, C20:4n-6) levels between any of the groups $(p=0.667, p=0.606)$. Principal component analysis (PCA) indicated MC4R and Elovl2 fatty acid levels were distributed in distinct clusters from CNTRL fish, where principal coordinate (PC) 1 explained $48.19 \%$ and PC 2 explained $28.52 \%$ of the variation (Figure $3 b$; Table 5 ). PCA indicated a correlation between DHA and ARA. 
Table 4

Mean eicosapentaenoic acid (EPA, C20:5n-3), docosahexaenoic acid (DHA, C22:6n3 ), alpha-Linolenic acid (ALA, C18:3n-3) and Arachidonic acid (ARA, C20:4n-6)

content (mg) per gram of muscle tissue in control (CNTRL), melanocortin-4 receptor

(MC4R) knockout and mc4r knockout + ccßA-msElovl2 transgene (Elovl2) knock-in channel catfish, Ictalurus punctatus. The ccßA-msElovl 2 transgene containing masu salmon, Oncorhynchus masou, elongase gene driven by the common carp, Cyprinus carpio, beta-actin promoter was inserted into the channel catfish melanocortin-4 receptor ( $m c 4 r$ ) gene using the two-hit two-oligo with plasmid

$(2 \mathrm{H} 2 \mathrm{OP})$ method. Muscle was sampled from 3 fish from each treatment. Mean EPA levels in Elov2 and MC4R fish were 122\% and 94\% higher than in controls ( $p=$ $0.045 ; p=0.025)$. There was no significant difference in DHA, ALA, ARA or total EPA+DHA levels between any of the groups $(p=0.368 ; p=0.667, p=0.606, p=$ $0.178)$

\begin{tabular}{|c|c|c|c|c|c|c|}
\hline \multicolumn{7}{|c|}{ Mean Fatty Acid Content in Muscle (mg/g) } \\
\hline & \multicolumn{2}{|c|}{ CNTRL $(n=3)$} & \multicolumn{2}{|c|}{$\operatorname{MC4R}(n=3)$} & \multicolumn{2}{|c|}{ Elovl2 (n=3) } \\
\hline & Mean & SD & Mean & SD & Mean & SD \\
\hline EPA $20: 5(n-3)$ & 0.51 & 0.33 & 0.99 & 0.52 & 1.13 & 0.70 \\
\hline DHA 22:6(n-3) & 1.31 & 0.60 & 1.59 & 0.59 & 1.74 & 0.71 \\
\hline ALA 18:3(n-3) & 0.04 & 0.05 & 0.02 & 0.02 & 0.01 & 0.01 \\
\hline ARA $20: 4(n-6)$ & 0.17 & 0.10 & 0.25 & 0.10 & 0.26 & 0.13 \\
\hline EPA+DHA & 1.82 & & 2.58 & & 2.87 & \\
\hline $\begin{array}{l}\text { Amount of fish }(\mathrm{g}) \text { required } \\
\text { to provide } 500 \mathrm{mg} \text { EPA+DHA }\end{array}$ & 274.73 & & 193.8 & & 173 & \\
\hline
\end{tabular}

Table 5

Loadings for the principal components responsible for variation in fatty acid levels between control (CNTRL), melanocortin-4 receptor (MC4R) knockout and mc4rknockout + ccßA-msElovl2 transgene (Elovl2) knock-in channel catfish, Ictalurus punctatus. Principal components were comprised of vectors eicosapentaenoic acid (EPA, C20:5n-3), docosahexaenoic acid (DHA, C22:6n-3), alphalinolenic acid (ALA, C18:3n-3) and arachidonic acid (ARA, C20:4n6). PCA was based on a correlation matrix.

\begin{tabular}{|lllll|}
\hline & PC1 & PC2 & PC3 & PC4 \\
\hline EPA & 0.1081917 & 0.7956247 & 0.5747578 & -0.1578902 \\
\hline DHA & 0.6699068 & -0.2006076 & -0.0443956 & -0.7134497 \\
\hline ARA & 0.6185815 & -0.2507954 & 0.4027744 & 0.6262838 \\
\hline ALA & -0.3960762 & -0.5136532 & 0.7109538 & -0.2717145 \\
\hline
\end{tabular}

\section{Discussion}

In the current study, the effects of microinjection of sgRNA targeting exon 1 of the channel catfish melanocortin-4 receptor gene in conjunction with cc $\beta A-m s E l o v 12$ elongase plasmid, ssODNs and Cas9 protein on mutation rate, growth, and omega-3 content were investigated. Efficient mutagenesis was achieved. There was high variability in mutation rate between both target sites with $49 \%$ of fish microinjected with MC4R-A having both the elongase insertion and mc4r deletion compared to $0 \%$ of MC4R-D fish. Microinjection of MC4R-A produced a $92 \%$ mutation rate in the mc4rgene. This is far higher than the $33 \%$ mutation rate achieved in our lab in 2017 , using the same sgRNAs (Coogan, 2021). The two major differences in protocol between this study and previous experiments are the $2 \mathrm{H} 2 \mathrm{OP}$ method and simultaneous insertion of the ccßA-msElovl2 transgene. The previous experiment used CRISPR/Cas9 with sgRNAs specifically designed to knockout the mc4rgene without adding in a transgene. Growth and overall omega- 3 content was $42 \%$ and $45 \%$ higher, respectively, in Elovl2 mutants than in controls.

Regarding mutation rate, Yoshimi et al. (2016) reported knockout mutations of $82.4 \%$ for the Rosa26 locus and integration of the green fluorescent protein (GFP) of $17.6 \%$ in rats, Rattus norvegicus. The $2 \mathrm{H} 2 \mathrm{OP}$ method, designed by Yoshimi et al. (2016), uses ssODNs as 
donor templates to facilitate homologous recombination (HR) rather than non-homologous end joining (NHEJ) to repair the double stranded break (DSB). NHEJ is the faster and typically more favored repair mechanism and is far more mutagenic, making it desirable for generating knockouts (Mao et al., 2008). However, by introducing a plasmid with ssODNs homologous to the cut site, the gap can quickly be filled with the plasmid, thereby preventing reconstitution of the original sequence (Yoshimi et al., 2016). Additionally, the 5' degradation of SSODNs by exonucleases and removal by helicase in the $2 \mathrm{H} 2 \mathrm{OP}$ method can lead to incomplete repair and cause a high rate of indel mutations (Yoshimi et al., 2016). The insertion of an entire transgene virtually guarantees complete knockout of the target gene and could cause greater phenotypic changes than smaller indels.

Growth was 42\% higher in Elovl2 mutants than in controls. Previous mc4r knockout channel catfish generated in our lab in 2017 were $18.9 \%$ larger than controls at a similar size ( $50 \mathrm{~g}$ ) to this study (Coogan, 2021) and $70 \%$ and $37 \%$ larger than controls at $600 \mathrm{~g}$ and $3 \mathrm{~kg}$, respectively, in initial aquaria experiments in 2016. This faster growth makes Elovl2 mutants a potentially high value genotype for commercial aquaculture. While these results are promising, the experiment was not performed under commercial settings and future research should evaluate whether there is a genotype $\times$ age or genotype $\times$ environment interaction. Additionally, as these fish were $\mathrm{P}_{1}$ generation and were very likely mosaics, future research should evaluate performance in the $F_{1}$ generation and the role of zygosity in growth.

Observed omega-3 fatty acid levels were increased in both Elovl2 mutants and MC4R mutants when compared to controls. Mean EPA levels in Elovl2 mutants and MC4R mutants were $121.6 \%$ and $94.1 \%$ higher than controls, respectively. Observed levels of DHA levels in Elovl2 mutants and MC4R mutants were $32.8 \%$ and $21.4 \%$ higher than controls, respectively. Overall observed levels of EPA+DHA were $45.1 \%$ and $4.3 \%$ higher in Elovl2 fish than controls and MC4R fish, respectively. This indicates that both mc4rand elongase play a key role in omega-3 synthesis. Fish typically have higher levels of DHA than EPA, and elongase plays a more essential role in DHA synthesis than in EPA synthesis, potentially explaining the larger relative increase in DHA in Elovl2 fish.

To obtain the recommended $500 \mathrm{mg}$ of EPA+DHA per day, the consumer would need to eat approximately $275 \mathrm{~g}$ of wild-type catfish. A typical serving of fish is $112 \mathrm{~g}$ (Kris-Etherton et al., 2009). Thus, a consumer would need to eat nearly three servings to reach recommended levels. With the Elovl2 genotype, a consumer would need to eat 1.69 servings of catfish per day to reach recommended levels of omega-3 fatty acids, nearly half that of the wild-type. While farmed Elovl2 catfish still have EPA and DHA levels far below those of fatty marine fish such as salmon and tuna, they also have fewer of the issues associated with these fish including high mercury levels, microplastics, and ecological disruption (Jackson et al., 2001; Burger et al., 2005; Lusher et al., 2017; Zupo et al., 2019).

The improved growth and omega-3 levels indicate that the use of Elovl2 channel catfish could be beneficial for commercial farms. Catfish farming and production in the USA peaked in 2003, dramatically declined from 2007-2012 and has been gradually increasing since that time (Hanson and Sites, 2015; Torrans and Ott, 2018; FAO, 2020). Gene editing and transgenesis presents a valuable tool to increase profitability, sustainability, and industry growth. There are, however, ethical, logistical, and regulatory hurdles for the Elovl2 mutant channel catfish to become applied commercially in the United States, as the FDA currently regulates gene edited animals. The improvement of gene editing technologies, greater understanding of its effects and the commercial success of genetically improved organisms make this technology a viable option in the near future. In the last few years AquaBounty transgenic salmon were approved for human consumption in the United States and Canada, Revivicor transgenic swine were approved by the FDA in the United States, Intrexon's gene edited tilapia were approved in Argentina, and Regional Fish Institute's gene edited sea bream were approved in Japan (Nordrum, 2019). By combining transgenesis and gene editing with other genetic techniques, such as selection, crossbreeding, and hybridization, it is likely possible to achieve even greater growth results, shorten the grow-out period and select for multiple traits. With an increasing human population and declining natural resources, all solutions should be evaluated to determine the most efficient and sustainable methods of food production.

\section{Materials And Methods}

\section{Ethical statement}

All experiments were conducted at the Fish Genetics Research Unit, E.W. Shell Fisheries Research Center, Auburn University, AL, USA. All experimental protocols used in this experiment were approved by the Auburn University Institutional Animal Care and Use Committee (IACUC) before the experiment was initiated and followed the Association for Assessment and Accreditation of Laboratory Animal Care (AAALAC) and Animal Research: Reporting of In Vivo Experiments (ARRIVE) guidelines.

\section{Design and preparation of sgRNA and CRISPR/Cas9 System}


A common carp $\beta$-actin promoter (Accession ID: M24113.1) was used to drive the expression of masu salmon elongase gene (Accesion ID: KC847063.1). An antifreeze polyA terminator from ocean pout, Zoarces americanus (Accession ID: S65567.1) was used to terminate transcription. This synthetic construct (ccßA-msElovl2), totaling 9,267bp, was built by GenScript (USA Inc., Piscataway, NJ 08854, USA). Two sets of two CRISPR short guide RNAs (sgRNA) plasmids were designed, targeting the coding region in exon one of the $m c 4 r$ gene in channel catfish (MC4R-A and MC4R-D) and the non-coding region adjacent to the protospacer adjacent motif (PAM) sequence of the transgene (PUC57) (Table 1). The corresponding cc $\beta A-m s E l o v l 2$ transgene was designed to contain two arms, upstream and downstream, for homologous recombination, matching the cuts created by the sgRNA. sgRNAs and ssODNs were constructed for 2H2OP insertion of cc $\beta A$-msElovl2 into mc4r locus (Table 1; Figure 1). Each of the oligos and plasmid was reconstituted using DNase/RNase Free water to $10 \mathrm{mM}$. The sgRNA templates were generated by synthesizing double stranded DNA through T7 run-off as described by Varshney et al. (2015) with modifications from Khalil et al. (2017). The two oligos were annealed using EconoTaqÒ Plus 2x Master Mix (Lucigen, Middleton, WI). The sgRNAs were synthesized using the Maxiscript T7 kit (Thermo Fisher Scientific), following the manufacture guidelines. The obtained sgRNAs were purified using Zymo RNA Clean and Concentrator kit (Zymo Research). The sgRNAs were stored in $-80^{\circ} \mathrm{C}$ freezer. The Cas 9 protein was acquired from PNA Bio (3541 Old Conejo Rd, Newbury Park, CA 91320) and reconstituted in $\mathrm{dH}_{2} 0$ to a concentration of $1 \mathrm{mg} / \mathrm{mL}$. The ccßA-msElovl2 plasmid was reconstituted to $250 \mathrm{ng} / \mu \mathrm{L}$. Each of the ssODNs were reconstituted to $100 \mathrm{ng} / \mu \mathrm{L}$. Twenty minutes prior to fertilizing the eggs, two sets of injection solutions were prepared by mixing $2 \mu \mathrm{L}(200 \mathrm{ng})$ of each pair of ssODN, $1 \mu \mathrm{L}$ ccßA-msElovl2 plasmid (125 ng), $1 \mu \mathrm{L}$ ccßA-msElovl2 sgRNA (PUC57) (300 ng), $1 \mu \mathrm{L}$ MC4R-(A or D) sgRNA (300 ng), $2 \mu \mathrm{L}$ Cas9 and $2 \mu \mathrm{L}$ phenol red (10\%) to a total volume of $11 \mu \mathrm{L}$.

\section{Brood stock selection, husbandry, selection, and spawning}

The Kansas strain of channel catfish was chosen as brood stock due to their superior growth and fry output when induced by injection of luteinizing hormone releasing hormone analogs ( $\mathrm{LHRHa}$ ). Brood stock were cultured in 0.04-ha earthen ponds averaging 1-meter in depth at a density of $3500 \mathrm{fish} / \mathrm{ha}$. They were fed a $32 \%$ protein catfish pellet at $1-2 \%$ of their body weight five days per week. Dissolved oxygen was maintained above $3 \mathrm{mg} / \mathrm{L}$ using a $1 / 2$ horsepower surface aerator (Air-O-Lator). Brood stock spawning followed the procedures described by Qin et al. (2016).

\section{Transgenic fish production}

Approximately 200-300 g of eggs were transferred to a greased pan for fertilization. Approximately $3 \mathrm{~mL}$ of sperm solution was added to the eggs and mixed gently with fingertips. Freshwater was added to barely cover the eggs to activate the sperm and eggs and the water was swirled to form a single layer and prevent sticking. After $2 \mathrm{~min}$, the eggs should be fertilized, and three more $\mathrm{cm}$ of water was added, and the eggs were left to harden for $15 \mathrm{~min}$. While the embryos were hardening, 5-10 $\mu \mathrm{L}$ of the injection mixture was loaded into $1.0 \mathrm{~mm}$ OD borosilicate glass capillary microinjection needles using a microloader. After 15 minutes 100-200 embryos were transferred in a single layer to a greased $100 \mathrm{~mm}$ petri dish and covered with Holtfreter's solution ( $59 \mathrm{mM} \mathrm{NaCl}, 0.67 \mathrm{mM} \mathrm{KCl}, 2.4 \mathrm{mM} \mathrm{NaHCO3,0.76} \mathrm{mM}$ $\mathrm{CaCl} 2,1.67 \mathrm{mM} \mathrm{MgSO}$ ) for microinjection. Microinjection procedure followed that described by Khalil et al. (2017) and Elaswad et al. (2018). Each embryo was injected with $5 \mathrm{~nL}$ of solution at the one cell stage. Control embryos were injected with $5 \mathrm{~nL}$ of $12 \%$ phenol red solution.

After microinjection, embryos were placed in $4 \mathrm{~L}$ tubs of Holtfreter's solution (Bart and Dunham 1996) with $10 \mathrm{mg} / \mathrm{L}$ doxycycline kept at $27^{\circ} \mathrm{C}$ with continuous aeration. The solution was changed, and dead embryos were removed daily. After about 5 days, or when the embryos were moving rapidly within the egg membrane and close to hatch, doxycycline treatment was discontinued. Fry were kept at 20 fry $/ L$ and fed Purina ${ }^{\circledR}$ AquaMax ${ }^{\circledR}$ powdered starter feed ( $50 \%$ crude protein, $17 \%$ crude fat, $3 \%$ crude fiber and $12 \%$ ash) (Purina Animal Nutrition LLC, Shoreview, MN) four times a day for two months. At 20 days post hatch, fry were moved to $60 \mathrm{~L}$ aquaria in recirculating aquaculture systems (RAS).

\section{Culture and growth}

Fry from each genetic type were stocked into 3-replicate $50 \mathrm{~L}$ aquaria in RAS for growth experiments. Fish were kept at a density of 2 fish/L. Feed size was adjusted as the fish grew. Fry were fed Aquaxcel WW Fish Starter 4512 ( $45 \%$ crude protein, $12 \%$ crude fat, $3 \%$ crude fiber and 1\% phosphorus) (Cargill Animal Nutrition, Minneapolis, MN) twice a day for four months. Juvenile fish were fed with WW 4010 Transition ( $40 \%$ crude protein, $10 \%$ crude fat, $4 \%$ crude fiber and $1 \%$ phosphorus) (Cargill Animal Nutrition, Minneapolis, MN) once a day. All fish were fed every day to satiation.

\section{Mutation Analysis}


At 6 months post-hatch, pelvic fin-clip samples $(10-20 \mathrm{mg})$ were collected in sterile $1.5 \mathrm{~mL}$ Eppendorf tubes and kept in a $-80^{\circ} \mathrm{C}$ freezer until DNA extraction. Genomic DNA was extracted using proteinase $\mathrm{K}$ digestion followed by protein precipitation and iso-propanol precipitation of DNA, as described by Kurita et al. (2004). DNA concentration and purity was measured using a NanoDrop 2000 spectrophotometer (Thermo Scientific) and concentration was adjusted to $500 \mathrm{ng} / \mu \mathrm{L}$.

To determine the presence of the transgene, the primer set Elovl2-F, Elovl2-R (Table 1) was designed using Primer3plus to amplify a partial sequence of the transgene. The Expand High FidelityPLUS PCR System (Roche) was used with $500 \mathrm{ng}$ of genomic DNA. A Bio-Rad T100 Thermal Cycler was used to run PCR amplification with the following procedure: initial denaturing at $95^{\circ} \mathrm{C}$ for 3 min, 34 cycles of denaturation at $95^{\circ} \mathrm{C}$ for $30 \mathrm{~s}$, annealing at $62^{\circ} \mathrm{C}$ for $40 \mathrm{~s}$ with a ramp speed of $-0.2^{\circ} \mathrm{C} / \mathrm{s}$, extension at $72^{\circ} \mathrm{C}$ for $40 \mathrm{~s}$; and final elongation at $72^{\circ} \mathrm{C}$ for $10 \mathrm{~min}$. The PCR product was confirmed with gel electrophoresis on a $1 \%$ TAE tris base, acetic acid, and EDTA agarose gel. The knock-in mutation was preliminarily identified by presence of the amplified DNA fragment.

The primer set MC4R-F and MC4R-R (Table 1) was designed using Primer3plus to encapsulate all possible mutation sites in the $m c 4 r$ gene. The PCR amplification procedure was as follows: initial denaturing at $95^{\circ} \mathrm{C}$ for $3 \mathrm{~min} ; 34$ cycles of denaturation at $95^{\circ} \mathrm{C}$ for $30 \mathrm{~s}$, annealing at $62^{\circ} \mathrm{C}$ for $40 \mathrm{~s}$ with a ramp speed of $-0.2^{\circ} \mathrm{C} / \mathrm{s}$, extension at $72^{\circ} \mathrm{C}$ for $40 \mathrm{~s}$; and final elongation at $72^{\circ} \mathrm{C}$ for $10 \mathrm{~min}$. The PCR product was confirmed on a 1\% TAE tris base, acetic acid, and EDTA agarose gel. The Surveyor ${ }^{\circledR}$ mutation detection kit (Integrated DNA Technologies, Coralville, IA) was used to detect mutations. The PCR product from the treatment fish was mixed with PCR product from a wild-type control of the same family at a 1:1 ratio. The combined product was then hybridized in a BioRad Thermocycler using the following procedure: Initial denaturing at $95^{\circ} \mathrm{C}$ for $3 \mathrm{~min} ; 95$ to $85^{\circ} \mathrm{C}$ at $-0.2^{\circ} \mathrm{C} / \mathrm{s}, 85$ to $25^{\circ} \mathrm{C}$ at $-0.2^{\circ} \mathrm{C} / \mathrm{s}$. Hybridized PCR products were mixed with Nuclease S, Enhancer S, MgCl2 and Reaction Buffer (2) according to kit instructions and incubated at $42^{\circ} \mathrm{C}$ for $1 \mathrm{~h}$. The digested products were separated on a 1.5\% TBE (tris borate EDTA) agarose gel and compared with that of control samples.

To confirm and identify the mutations, positive samples were sequenced, and the DNA cloned, using the TA cloning method. First, genomic DNA from mutants was amplified with PCR using Expand High Fidelity PLUS PCR System (Roche) using the above protocol. The PCR product was verified using a 1\% TAE agarose gel and cloned into the TOPO ${ }^{\circledR}$ TA Cloning ${ }^{\circledR}$ Kit (Invitrogen) with 20 clones per sample and sent to MCLabs for sequencing. Finally, the resulting sequences were interpreted using the MAFFT sequence alignment tool.

\section{Fatty Acid Analysis}

Muscle was sampled from 3 fish containing the Elovl2 transgene and mutated at the $m c 4 r$ gene, 3 fish containing the $m c 4 r$ mutation and not the Elovl 2 transgene, and 3 control fish with no mutation. Muscle samples were taken immediately after euthanizing the individual by pithing. They were then prepared for lipid extraction by first grinding into a slurry with a coffee grinder. Ground tissue (2g) was homogenized per extraction using a handheld tissue homogenizer until the tissue was sufficiently homogenized. Lipid extraction was performed using the chloroform-methanol protocol from Folch et al. (1957) and performed in triplicate for each sample. Extracts in hexane were kept in $2 \mathrm{~mL}$ borosilicate glass vials with PTFE caps and stored at $-20^{\circ} \mathrm{C}$ until they could be injected into a gas chromatograph (GC-MS7890A). The concentration of the fatty acid was measured using gas chromatography-mass spectrometry (GCMS, Agilent Technologies 7890A GC with 5975C MS) equipped with a DB-1701 GC column. Helium was used as the carrier gas. The initial temperature of the oven was set at $100^{\circ} \mathrm{C}$ for $5 \mathrm{~min}$, followed with a ramp of $4^{\circ} \mathrm{C} / \mathrm{min}$ to reach $250^{\circ} \mathrm{C}$ and then held for $10 \mathrm{~min}$. The detector was kept at $225^{\circ} \mathrm{C}$. Peaks were identified and quality check of the resulting spectra, and calculation of concentrations and was done by comparing sample retention times to a standard mix (Supelco® C4-24 Fatty Acid Methyl Ester (FAME) Mix; Lot: LRAC7954).

\section{Statistical analysis}

To calculate differences in body weight and fatty acid levels between ccßA-msElovl2 knockout/MC4R knock in mutants, mc4rknockout mutants and controls, a one-way ANOVA and Tukey's multiple comparisons test were performed using RStudio version 1.1.463 (R Core

Team, Vienna, Austria). Logistic regression was used to determine significant difference in mutation rates between MC4R-D and MC4R-A using RStudio. Principal component analysis (PCA) was plotted in RStudio using the ggplot2 3.1.0 package. PCA was based on a correlation matrix.

\section{Declarations}

\section{Acknowledgements}

The authors thank Professor Sushil Adhikari's research group and the Center for Bioenergy and Bioprodroducts at Auburn University and Professor D. Allen Davis' research group at Auburn University for assisting with the fatty acid composition. This project was partially

Page $10 / 15$ 
funded by USDA-NIFA award 2015-67015-23488 to Roger Cone and by an Ocean University China-Auburn University grant to Rex Dunham, Zhenkui Qin, and Baofeng Su.

\section{Author Contributions}

Michael Coogan conceived and designed the study, collected and analyzed data, generated and cultured the fish, and wrote the manuscript. De Xing developed the ccßA-msElovl2 plasmid containing the masu salmon, Onchorhynchus masou, elongase gene driven by the common carp $\beta$-actin promoter and assisted in fatty acid analysis. Boafeng Su was a supervisory team leader, developed the primers and analyzed the data. Veronica Alston, Andrew Johnson, Jinhai Wang, Shangjia Li, Wenwen Wang, Darshika Hettiarachchi, and Tasnuba Hasan collected data. Andrew Johnson, Jinhai Wang, Shangjia Li, De Xing, and Baofeng Su cultured fish. Mohd Khan, Ahmed Elaswad and Karim Khalil developed brood stock. Cuiyu Lu, Baofeng Su, Mohd Khan, and Mei Shang developed laboratory methodology. Zhenkui Qin and Roger Cone assisted with initial research stages of elongase research within our laboratory. lan Butts was a supervisory team member and assisted with statistical analyses. Rex Dunham was the principal investigator and assisted with writing. All authors have read and agreed to the published version of the manuscript.

\section{Competing Interests statement}

The authors declare no competing interests.

\section{Data Availability}

All data generated or analyzed during this study are included in this published article and its supplemental files.

\section{References}

1. Bart, A. N., \& Dunham, R. A. (1996). Effects of sperm concentration and egg number on fertilization efficiency with channel catfish (Ictalurus punctatus) eggs and blue catfish (I. furcatus) spermatozoa. Theriogenology, 45(3), 673-682.

2. Burger, J., Stern, A. H., \& Gochfeld, M. (2005). Mercury in commercial fish: optimizing individual choices to reduce risk. Environmental Health Perspectives, 113(3), 266-271.

3. Cheng, Q., Su, B., Qin, Z., Weng, C. C., Yin, F., Zhou, Y., ... \& Dunham, R. A. (2014). Interaction of diet and the masou salmon $\Delta 5-$ desaturase transgene on $\triangle 6$-desaturase and stearoyl-CoA desaturase gene expression and N-3 fatty acid level in common carp (Cyprinus carpio). Transgenic Research, 23(5), 729-742.

4. Coogan, M. (2021). Genetic Technologies for Growth Enhancement in Catfish (Doctoral dissertation, Auburn University).

5. Cuevas-Uribe, R., \& Tiersch, T. R. (2011). Estimation of fish sperm concentration by use of spectrophotometry. Cryopreservation in Aquatic Species, 2nd edition. World Aquaculture Society, Baton Rouge, LA, 162-200.

6. Curtis, K. R., McCluskey, J. J., \& Wahl, T. I. (2004). Consumer acceptance of genetically modified food products in the developing world. AgBioForum, 7(1\&2): 70-75

7. Du Sert, N. P., Ahluwalia, A., Alam, S., Avey, M. T., Baker, M., Browne, W. J., ... \& Würbel, H. (2020). Reporting animal research: Explanation and elaboration for the ARRIVE guidelines 2.0. PLoS Biology, 18(7), e3000411.

8. Dunham, R.A. (2011). Aquaculture and fisheries biotechnology: genetic approaches. CABI Wallingford, Oxfordshire, UK

9. Elaswad, A., Khalil, K., Cline, D., ...Cone, R., Dunham, R. (2018). Microinjection of CRISPR/cas9 protein into channel catfish, Ictalurus punctatus, embryos for gene editing. Journal of Visualized Experiments. 2018(131), e56275.

10. FAO (2020). The State of World Fisheries and Aquaculture 2020. Sustainability in action. Rome. https://doi.org/10.4060/ca9229en

11. Hanson, T. \& Sites, D. (2015). 2014 U.S. Catfish Database. MSU AEC Information Report. Retrieved from http://www.agecon.msstate.edu/whatwedo/budgets/docs/catfish2014.pdf

12. Hasan, M. R., \& Soto, S. Improving Feed Conversion Ratio and Its Impact on Reducing Greenhouse Gas Emissions in Aquaculture. FAO Non-Serial Publication 33 (FAO, Rome, 2017).

13. Huang, Y., W. Bugg, M. Bangs, G. Qin, D. Drescher, Nathan Backenstose, Chia Chen Weng, Yiliu Zhang, Karim Khalil, Sheng Dong, Ahmed Elaswad, Zhi Ye, Cuiyu Lu, Khoi Vo, R. M. Simora, X. Ma, Z. Taylor, Y. Yang, Tao Zhou, Jingping Guo, Guillaume Salze, Zhenkui Qin, Yi Wang, Rex A. Dunham (2021). Direct and Pleiotropic Effects of the Masou Salmon Delta5-Desaturase Transgene in F1 Channel Catfish (Ictalurus punctatus). Transgenic Research. 
14. Jackson, J. B., Kirby, M. X., Berger, W. H., Bjorndal, K. A., Botsford, L. W., Bourque, B. J., ... \& Warner, R. R. (2001). Historical overfishing and the recent collapse of coastal ecosystems. Science, 293(5530), 629-637.

15. Jiang, D. N., Li, J. T., Tao, Y. X., Chen, H. P., Deng, S. P., Zhu, C. H., \& Li, G. L. (2017). Effects of melanocortin-4 receptor agonists and antagonists on expression of genes related to reproduction in spotted scat, Scatophagus argus. Journal of Comparative Physiology $B, 187(4), 603-612$.

16. Kris-Etherton, P. M., Innis, S., \& Association, A. D. (2007). Position of the American Dietetic Association and Dietitians of Canada: dietary fatty acids. Journal of the American Dietetic Association, 107(9), 1599-1611.

17. Kurita, K., Burgess, S. M., \& Sakai, N. (2004). Transgenic zebrafish produced by retroviral infection of in vitro-cultured sperm. Proceedings of the National Academy of Sciences, 101(5), 1263-1267.

18. Lauritzen, L. (2001). The essentiality of long chain n-3 fatty acids in relation to development and function of the brain and retina. Prog Lipid Res, 40, 1-94.

19. Liu, R., Kinoshita, M., Adolfi, M. C., \& Schartl, M. (2019). Analysis of the role of the MC4R system in development, growth, and puberty of medaka. Frontiers in Endocrinology, 10, 213.

20. Lusher, A., Hollman, P., \& Mendoza-Hill, J. (2017). Microplastics in fisheries and aquaculture: status of knowledge on their occurrence and implications for aquatic organisms and food safety. FAO Fisheries and Aquaculture Technical Paper. No. 615. (FAO, Rome, 2017).

21. Meesapyodsuk, D., Reed, D. W., Covello, P. S., \& Qiu, X. (2007). Primary structure, regioselectivity, and evolution of the membranebound fatty acid desaturases of Claviceps purpurea. Journal of Biological Chemistry, 282(28), 20191-20199.

22. NMFS/NOAA (National Marine Fisheries Service - National Oceanic and Atmospheric Administration). (2013) Fisheries of the United States 2016. Current Fisheries Statistics No. 2016. NOAA, September 2013.

23. Nordrum, A. (2019). Transgenic salmon hits US Shelves. IEEE Spectrum, 57(1), 44-47.

24. Owens L (2012) Diseases. In: Lucas JS, Southgate PC (eds) Aquaculture: Farming Aquatic Animals and Plants, pp. 214-228. John Wiley \& Sons, New York, NY.

25. Peterman, M. A., \& Posadas, B. C. (2019). Direct economic impact of fish diseases on the East Mississippi catfish industry. North American Journal of Aquaculture, 81(3), 222-229.

26. Phelps, R. P., Hastey, R., Pendetar, A., Linley, L., Papanikos, N., \& Dunham, R. A. (2007). Effects of temperature on the induced spawning of channel catfish and the production of channel $\times$ blue catfish hybrid fry. Aquaculture, 273(1), 80-86.

27. Qin, Z., Li, Y., Su, B., Cheng, Q., Ye, Z., Perera, D. A., ... \& Dunham, R. A. (2016). Editing of the luteinizing hormone gene to sterilize channel catfish, Ictalurus punctatus, using a modified zinc finger nuclease technology with electroporation. Marine biotechnology, 18(2), 255-263.

28. Robinson, E. H., \& Li, M. H. (2015). Feed conversion ratio for pond-raised catfish. Mississippi Agricultural \& Forestry Experiment Station.

29. Saunders, A. V., Davis, B. C., \& Garg, M. L. (2013). Omega-3 polyunsaturated fatty acids and vegetarian diets. Medical Journal of Australia, 199, S22-S26.

30. Simopoulos, A. P. (2002). The importance of the ratio of omega-6/omega-3 essential fatty acids. Biomedicine \& Pharmacotherapy, 56(8), 365-379.

31. Smith, C. C., Harris, R. M., Lampert, K. P., Schartl, M., Hofmann, H. A., \& Ryan, M. J. (2015). Copy number variation in the melanocortin 4 receptor gene and alternative reproductive tactics the swordtail Xiphophorus multilineatus. Environmental Biology of Fishes, 98(1), 23-33.

32. Song, Y. \& Cone, R. D. 2007. Creation Of A Genetic Model Of Obesity In A Teleost. The Faseb Journal, $21,2042-2049$.

33. Sprecher, H. (2000). Metabolism of highly unsaturated n-3 and n-6 fatty acids. Biochem Biophys Acta, $1486,219-231$.

34. Stäubert, C., Tarnow, P., Brumm, H., Pitra, C., Gudermann, T., Gruters, A., Schöneberg, T., Biebermann, H. \& Römpler, H. (2007). Evolutionary aspects in evaluating mutations in the melanocortin-4 receptor. Endocrinology, 148, $4642-4648$.

35. Tekedar, H. C., Karsi, A., Williams, M. L., Vamenta, S., Banes, M. M., Duke, M., ... \& Lawrence, M. L. (2013). Complete genome sequence of channel catfish gastrointestinal septicemia isolate Edwardsiella tarda C07-087. Genome Announcements, 1(6).

36. Tucker, C. (2012). Channel catfish. Aquaculture Farming Aquatic Animals and Plants. 2nd Edition. pp. 365-383. Wiley-Blackwell, Sussex, UK. 
37. Varshney, G. K., Pei, W., LaFave, M. C., Idol, J., Xu, L., Gallardo, V., Carrington, B., Bishop, K., Jones, M., Li, M., Harper, U., Huang, S., Prakash, A., Chen, W., Sood, R., Ledin, J., \& Burgess, S. M. (2015). High-throughput gene targeting and phenotyping in zebrafish using CRISPR/Cas9. Genome research, 25(7), 1030-1042.

38. Wagner, B. A., Wise, D. J., Khoo, L. H. \& Terhune, J. S. (2002) The Epidemiology of Bacterial Diseases in Food-Size Channel Catfish, Journal of Aquatic Animal Health, 14:4, 263-272

39. Wall, R., Ross, R. P., Fitzgerald, G. F., \& Stanton, C. (2010). Fatty acids from fish: the anti-inflammatory potential of long-chain omega3 fatty acids. Nutrition Reviews, 68(5), 280-289.

40. Wang, S., Monroig, O., Tang, G., Zhang, L., You, C., Tocher, D. R., \& Li, Y. (2014). Investigating long-chain polyunsaturated fatty acid biosynthesis in teleost fish: Functional characterization of fatty acyl desaturase (Fads2) and Elovl5 elongase in the catadromous species, Japanese eel Anguilla japonica. Aquaculture, 434, 57-65.

41. Yoshimi, K., Kunihiro, Y., Kaneko, T., Nagahora, H., Voigt, B., \& Mashimo, T. (2016). ssODN-mediated knock-in with CRISPR-Cas for large genomic regions in zygotes. Nature Communications, $7(1), 1-10$.

42. Zhang, X., Huang, J., Qiu, H., \& Huang, Z. (2010). A consumer segmentation study with regards to genetically modified food in urban China. Food Policy, 35(5), 456-462.

43. Zhou, T., Yuan, Z., Tan, S., Jin, Y., Yang, Y., Shi, H., ... \& Gao, D. (2018). A review of molecular responses of catfish to bacterial diseases and abiotic stresses. Frontiers in Physiology, 9, 1113.

44. Zupo, V., Graber, G., Kamel, S., Plichta, V., Granitzer, S., Gundacker, C., \& Wittmann, K. J. (2019). Mercury accumulation in freshwater and marine fish from the wild and from aquaculture ponds. Environmental Pollution, 255, 112975.

\section{Figures}

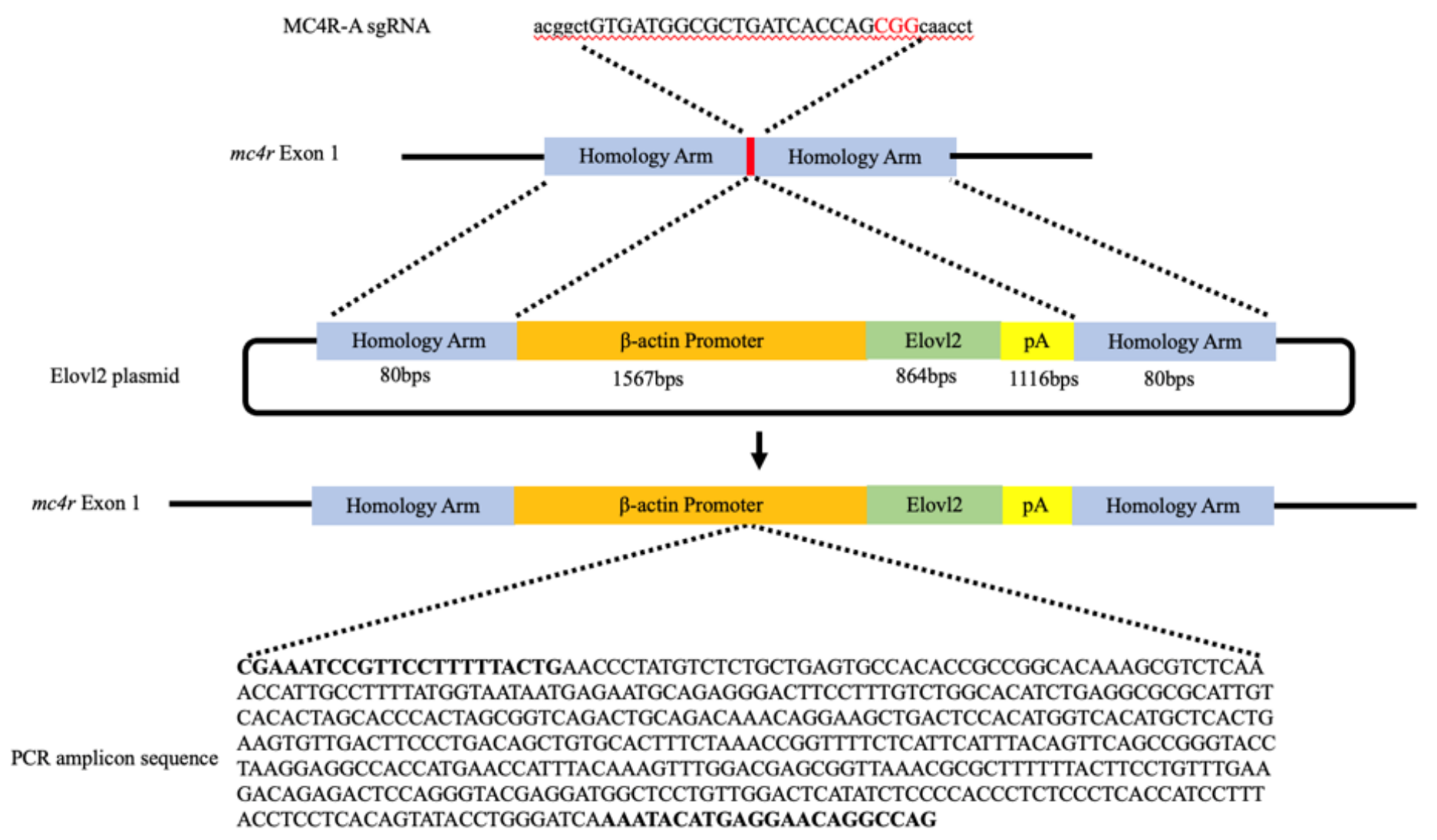

Figure 1

Schematic representation of the two-hit two-oligo with plasmid ( $2 \mathrm{H} 2 \mathrm{OP})$ method. First, Cas9, injected with two sgRNAs targeting exon 1 of the channel catfish, Ictalurus punctatus, melanocortin-4 receptor (mc4r) gene and the non-coding region adjacent to the protospacer 
a)

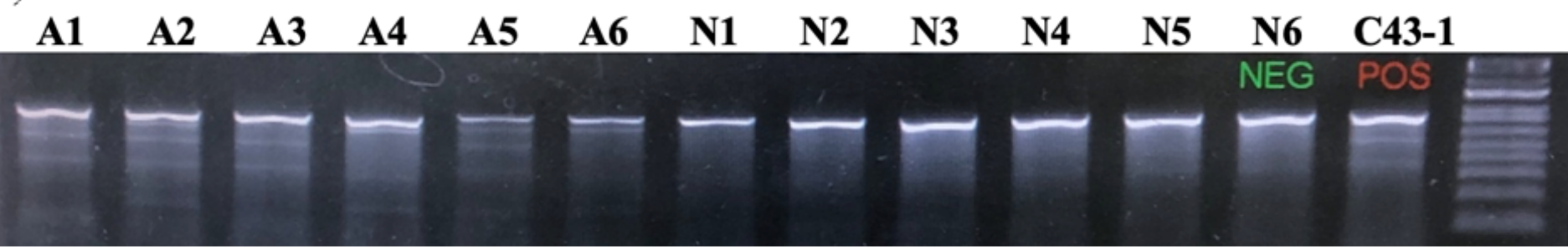

b).

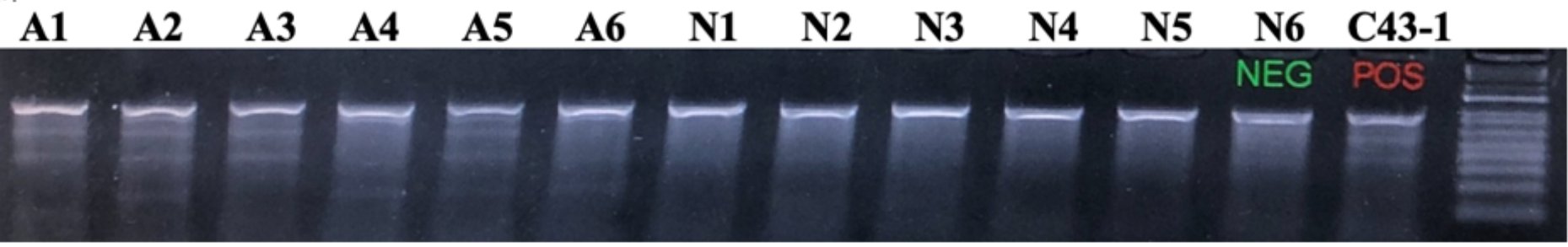

c)

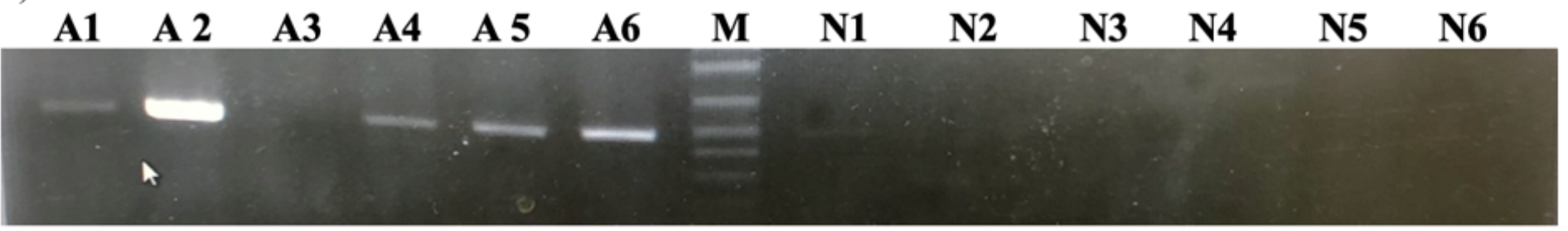

Figure 2

The ccßA-msElovl2 plasmid containing masu salmon, Oncorhynchus masou, elongase gene driven by the common carp, Cyprinus carpio, beta-actin promoter was inserted into the channel catfish melanocortin-4 receptor (mc4r) gene using the two-hit two-oligo with plasmid (2H2OP) method. Six (A1-A6) channel catfish, Ictalurus punctatus, were microinjected with MC4R-A sgRNA in conjunction with ccßA-msElovl2 plasmid (Table 1). $\mathrm{P}_{1}$ fish were generated in 2020. Approximately $50 \mathrm{~nL}$ of solution, composed of $1 \mu \mathrm{g} / \mu \mathrm{L}$ Cas $9 \mathrm{protein}(1$ $\mu \mathrm{L}), 400 \mathrm{ng} / \mu \mathrm{L}$ sgRNA MC4R-A $(0.5 \mu \mathrm{L}), 400 \mathrm{ng} / \mu \mathrm{L}$ sgRNA 2 (PUC57) (0.5 $\mu \mathrm{L}), 50 \mathrm{ng} / \mu \mathrm{L}$ donor plasmid $(1 \mu \mathrm{L}), 100 \mathrm{ng} / \mu \mathrm{L}$ ssODN1 (0.5 $\mu \mathrm{L}), 100 \mathrm{ng} / \mu \mathrm{L}$ ssODN2 $(0.5 \mu \mathrm{L})$ and $60 \%$ phenol red $(1 \mu \mathrm{L})$, was injected into each embryo close to the blastodisc 15 min after fertilization using a glass capillary needle. All six fish tested using Surveyor mutation detection kit were mutants. Six channel catfish (N1N6) were not injected to serve as controls. None of the controls showed a mutation in the mc4rgene. Sample C43-1 was previously identified as an mc4r mutant and was used as a positive control. The top row (a) was hybridized with wild-type by mixing equal volumes of sample PCR product with N6 negative control in order to identify homozygotes. The middle row (b) was not hybridized with wild-type in order to identify heterozygotes. In (a) and (b) multiple bands indicate a mutation in the mc4rtarget region. The bottom row (c) indicates PCR products using the Elovl2 primers. Numbers in a lane represent individual samples of fish. Five out of six channel catfish $(A 1, A 2, A 4, A 5, A 6)$ are positive for the ccßA-msElovl2 transgene as indicated by 485 bp band. Six channel catfish (N7-N12) served as non-inject controls. None of the controls tested positive for the transgene. $\mathrm{M}$ indicates $1 \mathrm{~kb}$ marker. Gel electrophoresis images shown here are cropped; full-length gels are presented in Supplemental Files Fig. S1. 

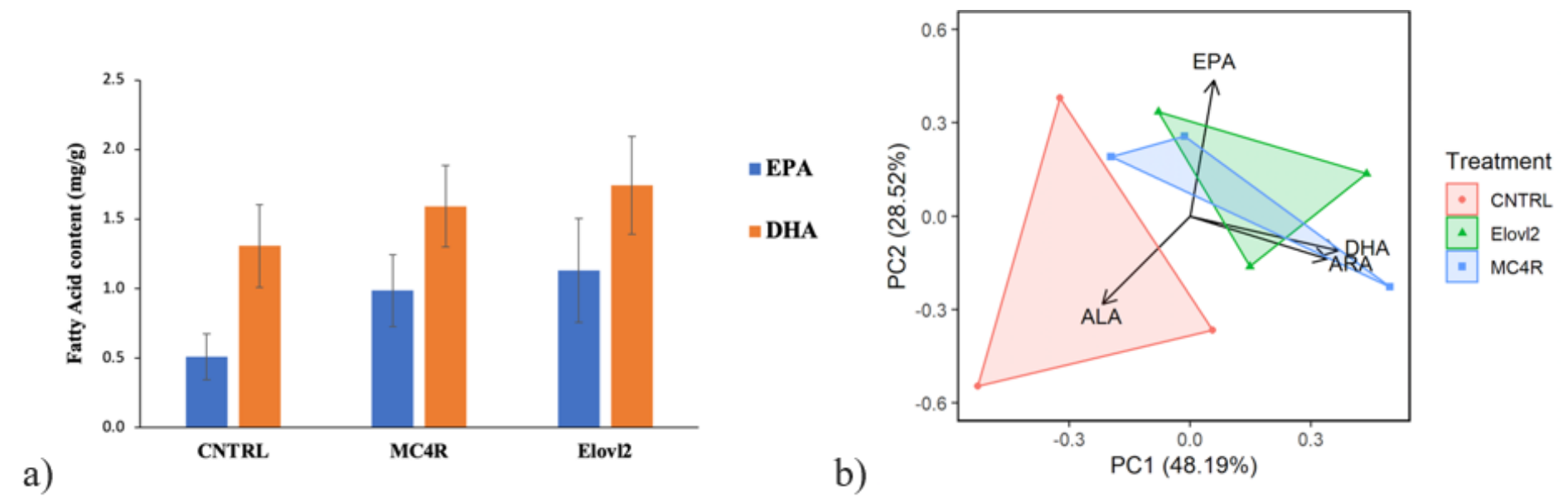

\section{Figure 3}

a) Mean eicosapentaenoic acid (EPA, C20:5n-3) and docosahexaenoic acid (DHA, C22:6n-3) content (mg) per gram of muscle tissue in control (CNTRL), melanocortin-4 receptor (MC4R) knockout and mc4r knockout + cc $\beta A-m s E l o v l 2$ transgene (Elovl2) knock-in channel catfish, Ictalurus punctatus. The ccßA-msElovl2 transgene containing masu salmon, Oncorhynchus masou, elongase gene driven by the common carp, Cyprinus carpio, beta-actin promoter was inserted into the channel catfish melanocortin-4 receptor ( $m c 4 r$ ) gene using the two-hit two-oligo with plasmid (2H2OP) method. Muscle was sampled from 3 fish from each treatment. Error bars indicate standard deviation. Mean EPA levels in Elov2 and MC4R fish were $122 \%$ and $94 \%$ higher than in controls $(p=0.045 ; p=0.025)$. There was no significant difference in DHA or total EPA+DHA levels between any of the groups $(p=0.368 ; p=0.178)$. b) Principal Component Analysis (PCA) of variation between CNTRL, MC4R and Elovl2 channel catfish. Principal components were comprised of vectors eicosapentaenoic acid (EPA, C20:5n-3), docosahexaenoic acid (DHA, C22:6n-3), alpha-linolenic acid (ALA, C18:3n-3) and arachidonic acid (ARA, C20:4n-6). PCA was based on a correlation matrix.

\section{Supplementary Files}

This is a list of supplementary files associated with this preprint. Click to download.

- ElongaseSupplementalFiles.docx 